\title{
Working memory and left medial temporal cortical thickness
}

\author{
Memória de trabalho e espessura cortical temporal medial esquerda \\ Giuseppe Pastura', Tadeu Takao Almodovar Kubo², Maria Angélica Regalla ${ }^{3}$, Cíntia Machado Mesquita ${ }^{3}$, \\ Gabriel Coutinho ${ }^{4}$, Emerson Leandro Gasparetto ${ }^{5}$, Otávio Figueiredo ${ }^{6}$, Paulo Mattos ${ }^{7}$, Alexandra Prüfer de \\ Queiroz Campos Araújo?
}

\begin{abstract}
Objective: To perform a pilot study to investigate the association between working memory and cortical thickness in a sample of attention deficit/hyperactivity disorder (ADHD) children. Methods: Seventeen children aged 7-10 years diagnosed with ADHD and 16 healthy children underwent a magnetic resonance scan for cortical thickness measurements. Data was correlated with working memory performance using the Backwards Digit Span subtest of the Wechsler Intelligence Scale for Children. Results: Working memory impairment, evidenced by lower scores on the Backwards Digit Span, was observed in patients with ADHD compared to healthy controls. There was a direct correlation between working memory and cortical thickness of the left medial temporal lobe (Spearman's correlation coefficient: 0.499; $p<0.005$ ). Conclusions: Our data suggests, for the first time, a correlation between working memory, evaluated by the Backwards Digit Span, and left medial temporal cortical thickness.
\end{abstract}

Keywords: attention deficit disorder with hyperactivity; child; memory.

\section{RESUMO}

Objetivo: Realizar estudo piloto para investigar a associação entre memória de trabalho e espessura cortical em crianças com transtorno de défict de atenção e hiperatividade (TDAH). Métodos: Dezessete crianças com TDAH, entre 7 e 10 anos, e dezesseis crianças saudáveis foram submetidas a ressonância magnética para aferição de espessura cortical. Os dados foram correlacionados com desempenho da memória de trabalho usando a ordem inversa do subteste Dígitos da Escala de Inteligência Wechsler para Crianças. Resultados: Prejuízos na memória de trabalho, evidenciado pela menor pontuação na ordem inversa do subteste Dígitos, foram observados em pacientes com TDAH, em comparação com crianças saudáveis. Observou-se correlação direta entre memória de trabalho e espessura do lobo temporal médio à esquerda (coeficiente de correlação de Spearman: 0,499; p < 0,005). Conclusões: Nossos dados sugerem, pela primeira vez, uma correlação entre memória de trabalho, avaliada através da pontuação na ordem inversa do subteste Dígitos, e espessura do córtex temporal medial à esquerda.

Palavras-chave: transtorno do déficit de atenção com hiperatividade; criança, memória.

Attention deficit/hyperactivity disorder (ADHD) is a frequent condition in childhood affecting around 5\% of school-age children ${ }^{1}$. Early cross-sectional studies indicated $4 \%$ to $5 \%$ reduction in total cerebral and cerebellar volumes in children and adolescents with ADHD, compared to typically developing children (TDC) ${ }^{2}$. Later findings suggested that the decrease is mainly due to reduced grey and white matter volumes and other regional abnormalities in the prefrontal cortex, especially the orbitofrontal and dorsolateral prefrontal cortices, basal ganglia, and cerebellum ${ }^{3}$. Attention deficit/hyperactivity disorder is a neurodevelopmental disorder with a remission rate of approximately $60 \%$ during late

\footnotetext{
${ }^{1}$ Universidade Federal do Rio de Janeiro, Faculdade de Medicina, Departamento de Pediatria, Rio de Janeiro RJ, Brasil;

${ }^{2}$ Clínica de Diagnóstico por Imagem (CDPI), Rio de Janeiro RJ, Brasil;

3Universidade Federal do Rio de Janeiro, Instituto de Psiquiatria, Rio de Janeiro RJ, Brasil;

${ }^{4}$ Centro de Neuropsicologia Aplicada/Instituto D`Or, Rio de Janeiro RJ, Brasil;

5Universidade Federal do Rio de Janeiro, Faculdade de Medicina, Departamento de Radiologia, Rio de Janeiro RJ, Brasil;

${ }^{6}$ Universidade Federal do Rio de Janeiro, Instituto COPPEAD, Rio de Janeiro RJ, Brasil;

${ }^{7}$ Universidade Federal do Rio de Janeiro, Faculdade de Medicina, Departamento de Psiquiatria, Rio de Janeiro RJ, Brasil.

Correspondence: Giuseppe Pastura; Departamento de Pediatria da Faculdade de Medicina da Universidade Federal do Rio de Janeiro; Rua Bruno Lobo, 50; Cidade Universitária; 21941-590 Rio de Janeiro RJ, Brasil; E-mail: giuseppe.pastura@ippmg.ufrj.br

Conflict of interest: There is no conflict of interest to declare.

Received 30 April 2016; Received in final form 02 June 2016; Accepted 13 June 2016.
} 
adolescence, meaning that symptoms subdue in a majority of cases, but not all. It has been shown that ADHD symptoms are correlated to the rate of cortical thinning in the medial and dorsolateral prefrontal cortex ${ }^{4}$.

Although not necessary for a clinical diagnosis, neuropsychological tests provide a better understanding of the cognitive profile of ADHD patients in clinical practice as well as contributing to a better understanding of the cognitive deficits of the disorder. Working memory (WM) deficits are well described in a myriad of disorders including $\mathrm{ADHD}^{5}$ and appear to be associated with a worse outcome, even when there is no comorbid learning disorder. The WM provides short-term storage and processing of sensory information. It has a critical role in guiding everyday behavior, underlying the ability to perform complex tasks such as learning, comprehension, reasoning, and planning ${ }^{6}$. It is noteworthy that behaviors associated with WM deficits might be the main complaints that lead ADHD individuals to seek treatment in specialized centers ${ }^{7}$.

The Digit Span subtest from the Wechsler Intelligence Scale for Children (WISC-III) ${ }^{8}$ is the most commonly used test in clinical practice to assess working memory, although some authors ${ }^{9}$ have questioned its sensitivity when milder deficits are present ${ }^{10}$.

The Digit Span test consists of progressively lengthier forward and backward repetitions of numbers ${ }^{8,11}$. The forward condition is considered a measure of the phonological loop whereas the backwards condition is considered a measure of central executive (i.e., working memory) given that it demands both storage and manipulation in order to retain and repeat the number in reverse order ${ }^{12}$.

Our group has previously demonstrated the importance of this test in discriminating between $\mathrm{ADHD}$ children and children with complaints of low academic performance referred for neuropsychological evaluation ${ }^{13}$.

Since patients with ADHD have reduced cortical thickness ${ }^{14}$, the aim of the present study is to investigate the correlation between WM and cortical thickness in ADHD children. To our knowledge, there is no previous correlation between those variables.

\section{METHODS}

After the institutional review board approval and parents' informed consent signature, 17 children of both genders, aged between seven and 10 years, were selected from the ADHD outpatient clinic of the Children's Hospital of the Federal University of Rio de Janeiro. All of them were drug-naïve and were diagnosed using DSM-IV criteria ${ }^{15}$. The ADHD module of the Kiddie-Schedule for Affective Disorders and Schizophrenia was used in order to confirm the diagnosis ${ }^{16,17}$. The DSM-5 criteria $^{18}$ had not yet been published when the study took place. As the new changes have occurred in relation to age of onset of symptoms (up to 12 years old) and a lower cutoff criterion for adults, our sample was not affected.

Sixteen gender- and age-matched TDC were selected from the elementary school of the same university. The K-SADS questionnaire was administered in order to exclude an $\mathrm{ADHD}$ diagnosis. Both groups underwent neuropsychological evaluation, including intelligence quotient (IQ) measurement and the Digit Span test from WISC-III.

A 3.0 Tesla scanner (Magnetom Verio, Siemens, Germany) with a 12 channel head coil was used to obtain MRI data. The imaging protocol images 3D gradient echo T1-sagittal plane, T2-weighted coronal plane, 3D FLAIR images in the sagittal plane and diffusion tensor (DTI) orthogonal directions in 30 gradients. Images were transferred to a workstation (CENTOS 4.9, Linux) with 8 GB of RAM memory and two Quad-Core Intel Xeon processors ( 2 x $3.2 \mathrm{GHz}$ ). FreeSurfer version 5.0.0 was used to perform cortical reconstruction (http://surfer.nmr. mgh.harvard.edu). The procedures included motion correction; removal of non-brain tissue using a hybrid watershed/surface deformation procedure; automated Talairach transformation; segmentation of subcortical white matter and deep gray matter structures, including the thalamus, hippocampus, amygdala, caudate, putamen, and ventricles; intensity normalization; tessellation of the gray matter/white matter boundary; automated topology correction; skull stripping and surface deformation and inflation of the cerebrum ${ }^{18}$. FreeSurfer software provided correction for motion in all images, reducing interference from movement during acquisition. Besides, an experienced neuroradiologist (ELG) and medical physicist (TTAK) accompanied all examinations and motion artifacts were excluded. Cortical thickness maps were calculated for each subject. The mean cortical thickness in regions-of-interest in the patient group and control group were computed and statistically compared $(\mathrm{p}<0.01)$ by a single-binary application included in the FreeSurfer distribution, Qdec, based on a General Linear Model. Correction for multiple comparisons was made by Qdec using Monte-Carlo simulation ( $p=0.05)$. Procedures for the accuracy of cortical thickness measurements were validated with histological analysis ${ }^{19,20}$. Age was included as a covariate ${ }^{21}$.

It is noteworthy that groups were corrected in the common error region of FreeSurfer, which included of the skull as gray matter. The criterion for surface reconstruction was that the red lines (gray matter) should cover the gray matter without invading the areas of white matter. All individuals suffered minor corrections of this segmentation. About $35 \%$ of both patients and controls underwent correction. Groups were blinded to the medical physicist. 
The Monte Carlo method provided correction for multiple comparisons and four brain cortical regions were appraised: left superior, medial and inferior temporal cortices, and left inferior parietal cortex. The non-parametric Mann-Whitney test was performed to analyze the difference between $\mathrm{ADHD}$ and TDC with regard to the measure of cortical thickness and the results of the Digit Span subtests - digit forwards and digit backwards. The Benjamini-Hochberg correction was used to calculate the false discovery rate for each of the p-values (Table 1).

\section{RESULTS}

The TDC and ADHD children were comparable in terms of age, gender, and intelligent quotient (IQ), as shown in Table 2.

The difference between TDC and ADHD children was significant for the four cortical regions mentioned above. Nevertheless, Digit Span scores were not statistically significant different between the groups of children.

Box-plots depicting differences in the groups' distributions according to cortical thickness of the left superior, medial and inferior temporal cortices, and left inferior parietal regions were represented in Figure 1.

Considering that no statistically significant difference between Digit Span scores of TDC and ADHD children was detected, scatter-plots showing correlations between cortical thickness and these scores were built taking both groups into account together (Figure 2).
Table 3 shows the correlation between the cortical thickness of each brain area selected and the values obtained in the Digit Span subtests (Spearman's correlation coefficient). Here, we observed a direct association between the scores on the Backwards Digit Span and thickness of the left medial temporal cortex (Spearman's correlation coefficient $=0.499$; significant at the 0.01 level; 2 -tailed). To a lesser extent, we observed the same association with the left inferior temporal cortex (Spearman's correlation coefficient $=0.388$; significant at the 0.05 level; 2 -tailed).

\section{DISCUSSION}

Our findings have shown a direct relationship between cortical thickness of the left medial temporal cortex and working memory, evaluated through the Backwards Digit Span test. The correlation of WM with the left inferior temporal cortical thickness was also observed, but to a lesser extent. No correlation was observed between the Forward Digit Span and cortical thickness in these brain regions.

This last result is in accordance with previous studies that discuss the validity of using both Digit Span conditions - forwards and backwards - separately, since they involve different neuropsychological circuits ${ }^{22}$ and only the reverse condition addresses working memory ${ }^{13}$.

Traditionally, the frontal lobes are recognized as responsible for the control of complex cognitive processes such

Table 1. Values of cortical thickness and Digit Span scores in children with attention deficit/hyperactivity disorder (ADHD) and typically developing children (TDC).

\begin{tabular}{|c|c|c|c|c|c|}
\hline Region & ADHD & TDC & Mann-Whitney U & $p$-value & BH corrected ( $p$-value) \\
\hline Left superior temporal cortex* & 2.5 & 2.9 & 30.5 & 0.000 & 0.000 \\
\hline Left medial temporal cortex* & 3.1 & 3.5 & 22.0 & 0.000 & 0.000 \\
\hline Left inferior temporal cortex* & 2.9 & 3.4 & 65.0 & 0.010 & 0.015 \\
\hline Left inferior parietal cortex* & 2.5 & 3.0 & 21.0 & 0.000 & 0.000 \\
\hline Forward Digit Span & 7.2 & 7.1 & 134.5 & 0.958 & 0.956 \\
\hline Backwards Digit Span & 3.6 & 4.2 & 84.0 & 0.063 & 0.061 \\
\hline
\end{tabular}

* in mm; BH: Benjamini-Hochberg correction for multiple comparisons.

Table 2. Comparison between the variables of age, gender and intelligence quotient (IQ) in children with attention deficit/ hyperactivity disorder (ADHD) and typically developing children (TDC).

\begin{tabular}{lccc}
\hline Variable & ADHD & TDC & p-value \\
\hline Gender (Male/Female) & $13 / \mathrm{abr}$ & $12 / \mathrm{abr}$ & 1.000 \\
Age $^{*}$ & $8(1.2)$ & $9(1.3)$ & 0.368 \\
$\mathrm{IQ}^{*}$ & $105(13.6)$ & $106(17.5)$ & 0.639 \\
\hline
\end{tabular}

"Medial (standard deviation). 

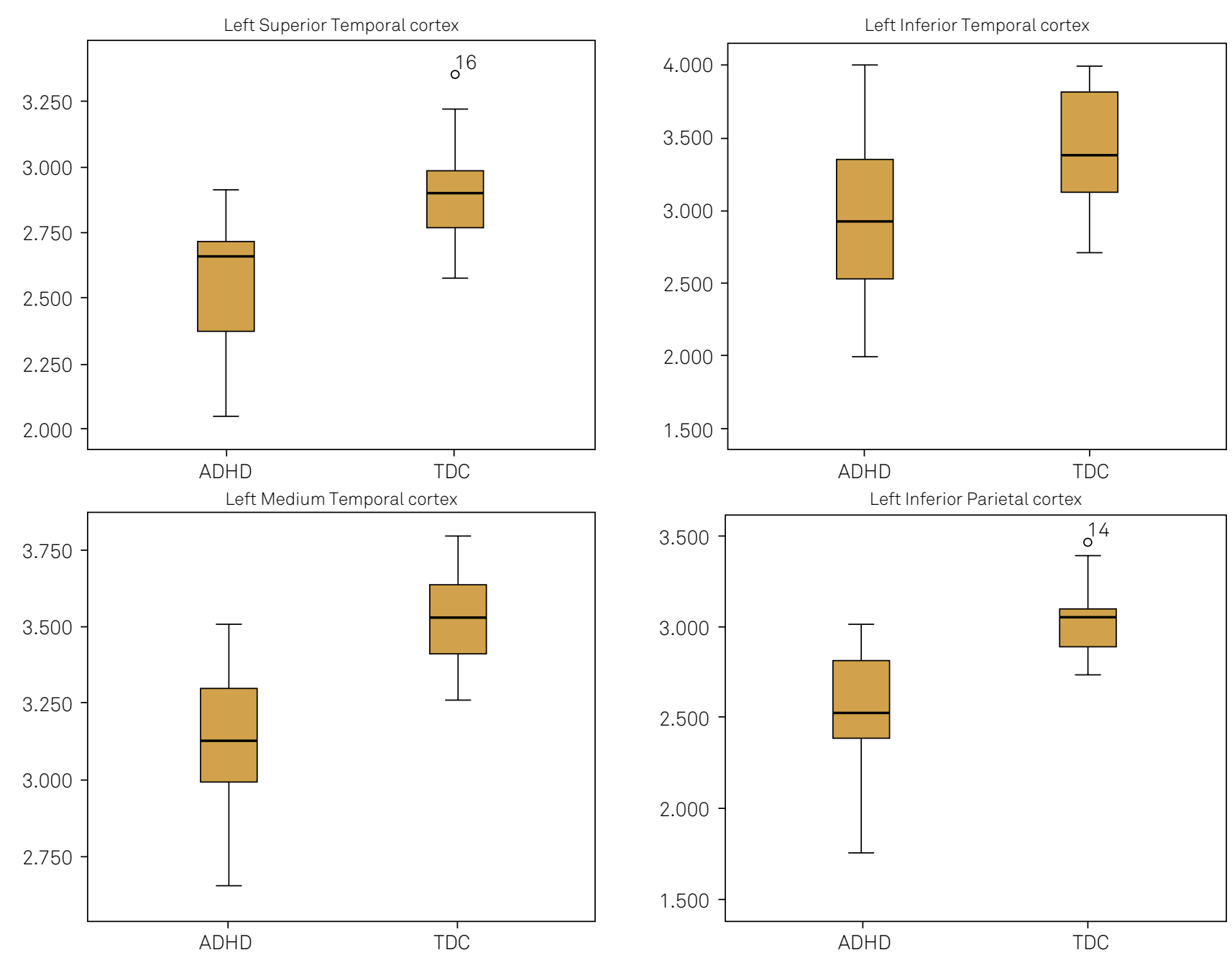

ADHD: Attention deficit/hyperactivity disorder; TDC: typically developing children.

Figure 1. Box-plots depicting differences in distributions between the groups according to cortical thickness of left superior, medial and inferior temporal cortices, and left inferior parietal regions.

Table 3. Values of Spearman's correlation coefficient between cortical thickness of each brain area selected and the values obtained in the Digit Span test.

\begin{tabular}{|ccc|}
\hline Region & $\begin{array}{c}\text { Forward } \\
\text { digit span }\end{array}$ & $\begin{array}{c}\text { Backwards } \\
\text { digit span }\end{array}$ \\
\hline Left superior temporal cortex & & \\
Spearman's coefficient & -0.196 & $0.322^{\star}$ \\
\hline Sig. (2-tailed) & 0.274 & 0.067 \\
\hline BH corrected p-value & 0.419 & 0.089 \\
Left medial temporal cortex & & \\
Spearman's coefficient & -0.190 & $0.499 \star \star$ \\
\hline Sig. (2-tailed) & 0.288 & 0.003 \\
\hline BH corrected p-value & 0.419 & 0.012 \\
\hline Left inferior temporal cortex & & \\
\hline Spearman's coefficient & -0.181 & $0.388 *$ \\
\hline Sig. (2-tailed) & 0.314 & 0.026 \\
\hline BH corrected p-value & 0.419 & 0.052 \\
\hline Left inferior parietal cortex & & \\
\hline Spearman's coefficient & -0.026 & 0.136 \\
\hline Sig. (2-tailed) & 0.886 & 0.451 \\
\hline BH corrected p-value & 0.886 & 0.451 \\
\hline
\end{tabular}

Sig.: significant; $\mathrm{BH}$ : Benjamini-Hochberg; ${ }^{*}$ Correlation is significant at the 0.10 level (2-tailed); ${ }^{*}$ Correlation is significant at the 0.05 level (2-tailed); ${ }^{* * *}$ Correlation is significant at the 0.01 level (2-tailed). as decision-making, planning and sustained attention ${ }^{23}$. However, more recently, there has been strong evidence indicating the contribution of the medial temporal lobe to $\mathrm{WM}^{24,25,26,27}$. In a less robust manner, the inferior temporal lobe's role in WM has also been demonstrated ${ }^{28}$.

According to the classic definition, WM relies on three interconnected subsystems: the phonological loop, responsible for the initial processing and storage of verbal information, the visual sketchpad, responsible for the initial processing of nonverbal information; and the episodic buffer, responsible for the connection of the information between the former systems ${ }^{29}$. The frontotemporal pathways play an important role in integrating these three subsystems of $\mathrm{WM}^{30}$.

The role of the medial temporal lobe in WM is not fully elucidated, as there are studies demonstrating that this region influences WM only when the task depends more on long-term memory processes ${ }^{31}$.

Our sample size should be considered a limitation to the study and the results may not be generalized. A larger sample 

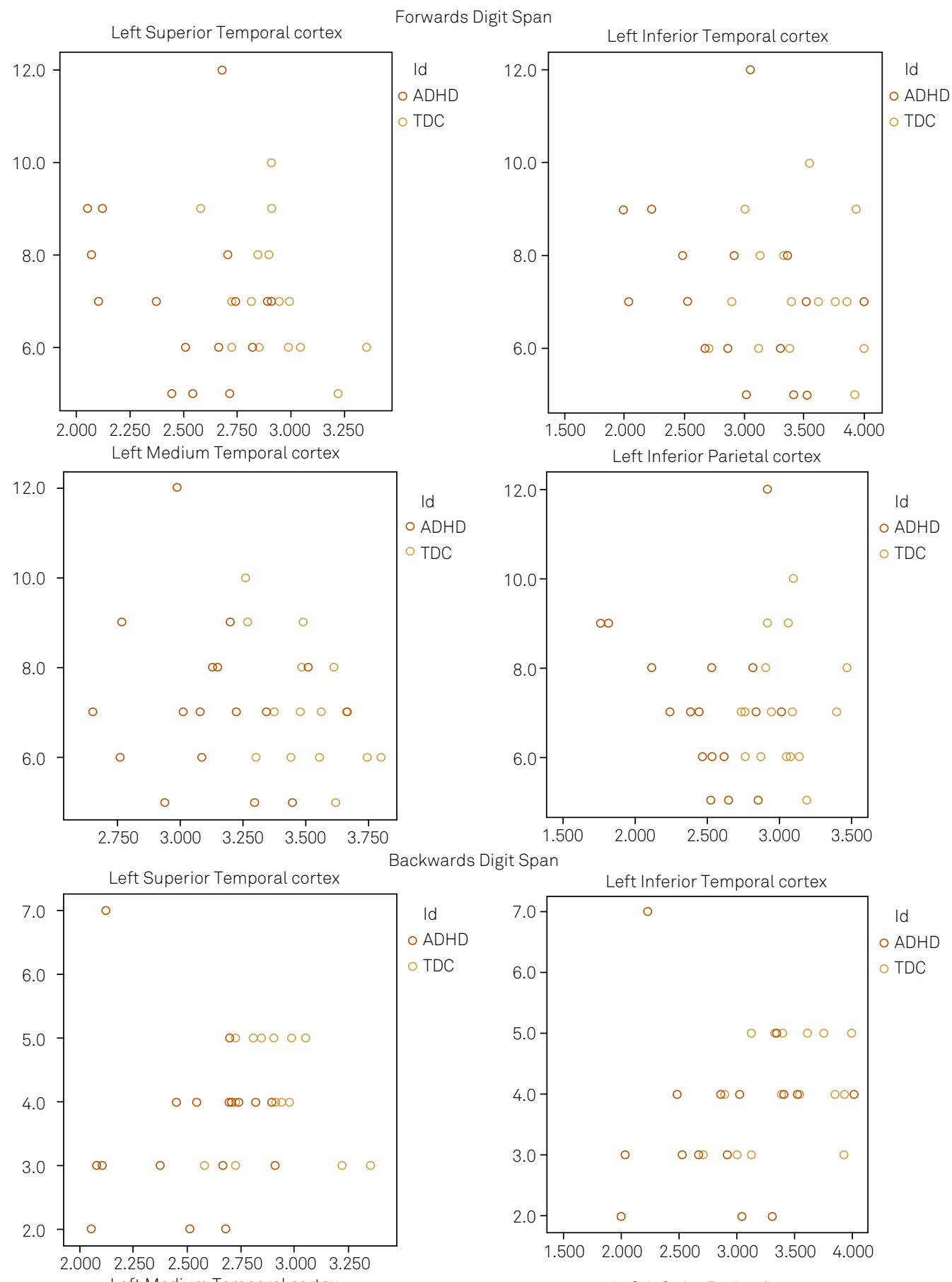

Backwards Digit Span

Left Inferior Temporal cortex
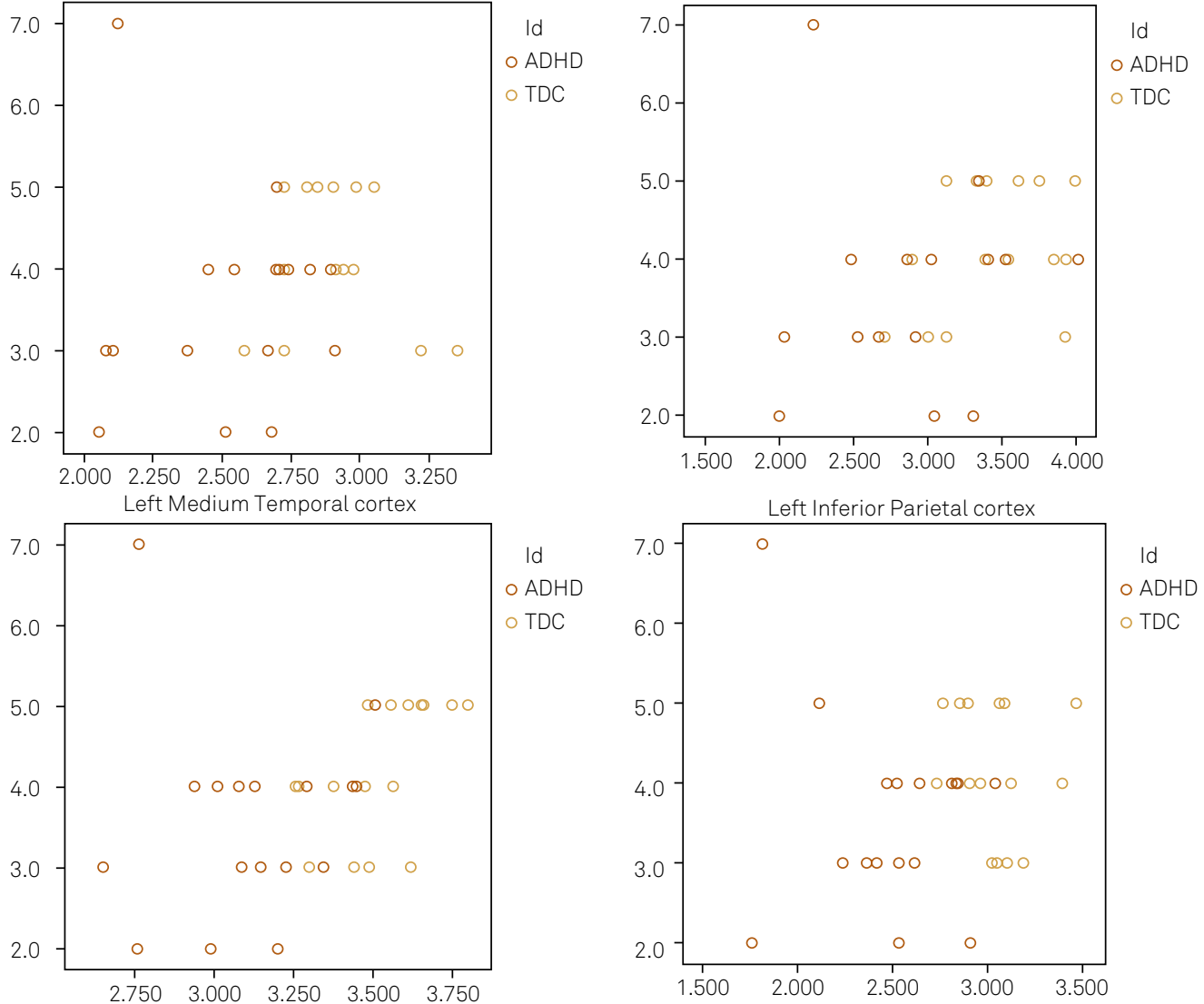

Figure 2. Scatter-plots showing correlations between cortical thickness and Digit Span scores (Forward and Backward) in both groups together. 
might show a statistically significant difference between the Backwards Digit Span scores of TDC and ADHD children. Although many steps were taken to minimize movement bias during examinations, head motion in ADHD patients can be considered a problem and a limitation of this study.
This pilot study was not able to confirm that working memory problems can differentiate ADHD from TDC. Nevertheless, our results suggest, for the first time, a direct correlation between the Backwards Digit Span and left medial temporal cortical thickness.

\section{References}

1. Polanczyk GV, Willcutt EG, Salum GA, Kieling C, Rohde LA. ADHD prevalence estimates across three decades: an updated systematic review and meta-regression analysis. Int J Epidemiol. 2014;43(2):434-42. doi:10.1093/ije/dyt261

2. Castellanos FX, Lee PP, Sharp W, Jeffries NO, Greenstein DK, Clasen LS et al. Developmental trajectories of brain volume abnormalities in children and adolescents with attention deficit/hyperactivity disorder. JAMA. 2002;288(14):1740-8. doi: 10.1001/jama.288.14.1740

3. Frodl T, Skokauskas N. Meta-analysis of structural MRI studies in children and adults with attention deficit hyperactivity disorder indicates treatment effects. Acta Psychiatr Scand. 2012;125(2):114-26. doi:10.1111/j.1600-0447.2011.01786.x

4. Shaw P, Malek M, Watson B, Greenstein D, Rossi P, Sharp W. Trajectories of cerebral cortical development in childhood and adolescence and adult attention-deficit/hyperactivity disorder. Biol Psychiatry. 2013;74(8):599-606. doi:10.1016/j.biopsych.2013.04.007

5. Kaufman AS, Lichtenberger EO. Essentials of WAIS-III Assessment. New York: John Wiley \& Sons; 1999.

6. Baddeley AD. Working memory, thought, and action. New York: Oxford University Press; 2007.

7. Cockcroft K. Working memory functioning in children with attention-deficit/hyperactivity disorder (ADHD): a comparison between subtypes and normal controls. J Child Adolesc Ment Health. 2011;23(2):107-18. doi:10.2989/17280583.2011.63454

8. Wechsler DW. WISC III: escala de Inteligencia Wechsler para crianças: manual. 3a ed. São Paulo: Casa do Psicologo; 2002.

9. Groth-Marnat G, Baker S. Digit Span as a measure of everyday attention: a study of ecological validity. Percept Mot Skills. 2003;97(3 Pt 2):1209-18. doi:10.2466/PMS.97.8.1209-1218

10. Martinussen R, Hayden J, Hogg-Johnson S, Tannock R. A meta-analysis of working memory impairments in children with attentiondeficit/hyperactivity disorder.J Am Acad Child Adolesc Psychiatry. 2005;44(4):377-84. doi:10.1097/01.chi.0000153228.72591.73

11. Figueiredo VLM. Adaptação e padronização Brasileira da escala de inteligência Wechsler para crianças, terceira edição - WISC-III. São Paulo: Casa do Psicólogo; 2002.

12. Rosenthal EN, Riccio CA, Gsanger KM, Jarratt KP. Digit Span components as predictors of attention problems and executive functioning in children. Arch Clin Neuropsychol. 2006;21(2):131-9. doi:10.1016/j.acn.2005.08.004

13. Coutinho G, Mattos P, Malloy-Diniz LF. Neuropsychological differences between attention deficit hyperactivity disorder and control children and adolescents referred for academic impairment. Rev Bras Psiquiatr. 2009;31(2):141-4. doi:10.1590/S1516-44462009000200011

14. Shaw P, Eckstrand K, Sharp W, Blumenthal J, Lerch JP, Greenstein $D$ et al. Attention-deficit/hyperactivity disorder is characterized by a delay in cortical maturation. Proc Natl Acad Sci USA. 2007;104(49):19649-54. doi:10.1073/pnas.0707741104

15. American Psychiatric Association. Diagnostic and statistical manual of mental disorders, $4^{\text {th }}$ edition (DSM-IV). Washington, DC: American Psychiatric Association; 1994.

16. Kaufman J, Birmaher B, Brent D, Rao U, Ryan N. The Schedule for affective disorders and schizophrenia for school-age children. Pittsburgh: University of Pittsburgh Medical Center; 1996.
17. Brasil HHA, Bordin IA. Convergent validity of K-SADS-PL by comparison with CBCL in a Portuguese speaking outpatient population. BMC Psychiatry. 2010;10(1):83. doi:10.1186/1471-244X-10-83

18. American Psychiatric Association. Diagnostic and statistical manual of mental disorders, $5^{\text {th }}$ edition (DSM-V). Washington, DC: American Psychiatric Association; 2013.

19. Desikan RS, Ségonne F, Fischl B, Quinn BT, Dickerson BC, Blacker D et al. An automated labeling system for subdividing the human cerebral cortex on MRI scans into gyral based regions of interest. Neuroimage. 2006;31(3):968-80. doi:10.1016/j.neuroimage.2006.01.02

20. Kuperberg GR, Broome MR, McGuire PK, David AS, Eddy M, Ozawa F et al. Regionally localized thinning of the cerebral cortex in schizophrenia. Arch Gen Psychiatry. 2003;60(9):878-88. doi:10.1001/archpsyc.60.9.878

21. Shaw P, Lerch J, Greenstein D, Sharp W, Clasen L, Evans A et al. Longitudinal mapping of cortical thickness and clinical outcome in children and adolescents with attention-deficit/hyperactivity disorder. Arch Gen Psychiatry. 2006;63(5):540-9. doi:10.1001/archpsyc.63.5.540

22. Salat DH, Buckner RL, Snyder AZ, Greve DN, Desikan RS, Busa E et al. Thinning of the cerebral cortex in aging. Cereb Cortex. 2004;14(7):721-30. doi:10.1093/cercor/bhh032

23. Ramsay MC, Reynolds CR. Separate digits tests: a brief history, literature review, and a reexamination of the factor structure of the Test of Memory and Learning (TOMAL). Neuropsychol Rev.1995;5(3):151-71. doi:10.1007/BF02214760

24. Gilbert SJ, Burgess PW. Executive function. Curr Biol. 2008;18(3):R110-4. doi:10.1016/j.cub.2007.12.014

25. Axmacher N, Schmitz DP, Wagner T, Elger CE, Fell J. Interactions between medial temporal lobe, prefrontal cortex, and inferior temporal regions during visual working memory: a combined intracranial EEG and functional magnetic resonance imaging study. J Neurosci. 2008;28(29):7304-12. doi:10.1523/JNEUROSCI.1778-08.2008

26. Axmacher N, Elger CE, Fell J. Working memory-related hippocampal deactivation interferes with long-term memory formation. J Neurosci. 2009;29(4):1052-60. doi:10.1523/JNEUROSCI.5277-08.2009

27. Cashdollar N, Duncan JS, Duzel E. Challenging the classical distinction between long-term and short-term memory: reconsidering the role of the hippocampus. Future Neurol. 2011;6(3):351-62. doi:10.2217/fnl.11.12

28. Stretton J, Winston G, Sidhu M, Centeno M, Vollmar C, Bonelli $S$ et al. Neural correlates of working memory in Temporal Lobe Epilepsy: an fMRI study. Neuroimage. 2012;60(3):1696-703. doi:10.1016/j.neuroimage.2012.01.126

29. Ranganath C, Cohen MX, Dam C, D'Esposito M. Inferior temporal, prefrontal, and hippocampal contributions to visual working memory maintenance and associative memory retrieval.J Neurosci. 2004;24(16):3917-25. doi:10.1523/JNEUROSCI.5053-03.2004

30. Baddeley A. Working memory and language: an overview. J Commun Disord. 2003;36(3):189-208. doi:10.1016/S0021-9924(03)00019-4

31. Stretton J, Thompson PJ. Frontal lobe function in temporal lobe epilepsy. Epilepsy Res. 2012;98(1):1-13. doi:10.1016/j.eplepsyres.2011.10.009 